International Journal of Engineering \& Technology, $7(4.33)(2018) 241-244$
SPC
International Journal of Engineering \& Technology
Website $w w w . s c i e n c e p u b c o . c o m / i n d e x . p h p / I J E T$
Research paper

\title{
Semiotics at Discursive Texts and Images in Online News
}

\author{
Heri Heryono*, Helmy Faisal \\ Informatics Engineering Department, Engineering Faculty of Widyatama University Bandung \\ *Corresponding author E-mail: heri.heryono@widyatama.ac.id
}

\begin{abstract}
The paper established an inappropriate relationship of text and image that should interact in one whole package of online news. It applied Semiotics analysis to go under the problems occurred. The analysis was developed to respond the question: why should be the text and image in online news associated? Do they match? Developed in three levels of analysis processes-analysis of relevant engagement in text and image; extended analysis of discursive relationship involved in news that turned to hoax; the intention of attaching the misplaced image to the text. This paper used qualitative Semiotics analysis to illustrate malfunction of text and image in online news. It is wished to be able to enhance the accuracy of a news.
\end{abstract}

Keywords: Semiotics; online news; discursive.

\section{Introduction}

Paperless based information has been integrated flourish since internet covered information system. One of the most interjected areas of this internet coverage is news. Online news is more popular than conventional newspaper. It has real time events, since the timeline of the online news is very rapid and variably different every second according to the real events. People will tremendously change their habit in getting information by this system, then leave the conventional system. The problem appeared in this online news is correlative contents, between the headline and article with image. It should be suitable in purpose, but in some cases in online news, it has apocryphal matters or in other words, it is a hoax.

Semiotics appears to analyse this phenomenon of apocryphal matters between pictures (image) with news article or headline (text) Saussure through Course in General Linguistics, first published in 1916, he postulated the existence of a common science of signs, or Semiology, of which linguistics would form only one part. Semiology aims to take in any system of signs, whatever their substances and limits; images, gestures, musical sounds, objects, and the complex associations of all these, which form the content of ritual, convention or public entertainment: these constitute, if not languages, at least systems of signification [1].

By technology which has been going advance, especially to the media of information, internet appeared and was introduced to people became the most powerful matter and equipment in which people might use for every aspect of people necessity related to the information technology. It has converted publication of the news from printed news (paper) to be online (paperless). This platform development of media information gave a possibility the time efficiency escalation through data withdrawing of recent or real time events with the most identical timeline, from the beginning of the occurrence until the end. The efficiency probability of time has raised the requirement of obtaining news. It fastened the acquisition of people necessity through areal time news.

It made additional features popped out and people demanded more to their requirement, especially news. Nowadays, people live be- tween reality and unreality of news package. The reality could be obtained from the textual language put in the article and headline, the unreality matter would be obtained from image or photo put in the news as the comprehensive references supported the articles.

It is aimed to give empirical experience to the readers by inserting image or picture that supports the article. But in fact, some news has implicitly put the wrong pictures or images. It is also purposed to make the readers believe of what they have read.

By this obligation of inputting image as the news providing supplementary, it should be arranged by the formal and fix rules. The procedure of inserting pictures or images in the news article, or as the headline of the news, should be filtered by recent reliable authority. This reduction of filtering by particular authority might emerge a possibility of inaccuracy between the content of the news with the image that is showed in it. It could be inferred that the truth is only one-sided validity, and it is not factual. It would make some possibilities of hoax-ness news appear.

\section{Related Works}

Text and image had been known as a primordial communication tools used by human. Those non-verbal aspects of language had their own interaction and binding energy to complete each other as one package in giving information. Nowadays, newspaper represents those linguistics aspect contained text and image as the attractive point to the readers.

Some media, especially readable media, offer some ownership to reader as if they are involved in the situation and so the reader nowadays become much judgmental toward news. They unfortunately need no code-encryption of articles they have read, by correlating image and text, they perceive an interconnection between couple things inside. In addition, people involved in communication do not actually share common codes and positions in social [8].

Different types of newspapers attract different kinds of audiences. They are thus perceptibly different at the level of the signifier, i.e. in how they are put together, in what kind of language they use (in the headline style and in the actual writing of stories), and in how 
they present their written text (type font, size of fonts, types of photography used, etc.) [2]. Several newspapers provide information by giving very actual image as the supportive aspect. On the other hands, the image itself has a dispelled meaning to the text brought together in one whole package. Images, however, are used to enhance the credibility of the news that is presented to the reader. As the pictures or images depict reality, they also furnish evidence to show the authenticity of a news story or give proof of an event that happened.

As Parkin hypothesis of interpretative social groups involved in reading codes within news defined by three groups [9]:

1. Dominant (or 'hegemonic') reading: it comes with very intensive sharing timeline for the people who are categorized at this level. They accept codes then reproduce the preferred reading (a reading which may not have been the result of any conscious intention on the part of the author(s)) - in such a stance the code seems 'natural' and 'transparent';

2. Negotiated reading: the people at this level tend to be the filter of media/news. They do not share the raw codes as common internet users do. They somehow resist those codes and modify them in a way of others can accept logically. They apply their basic knowledge, references and experience due to get point of view at any articles they have read before they re-convey them. It because reflects their own position in society and it will affect their social life if somehow they share incorrect information.

3. Oppositional ('counter-hegemonic') reading: the reader whose social situation places them in a directly oppositional relation to the dominant code, understands the preferred reading but does not share the text's code and rejects this reading, bringing to bear an alternative frame of reference (radical, feminist etc.) (e.g. when watching a television broadcast produced on behalf of a political party they normally vote against).

Based on Eco's analysis in the term of iconicity; it could be said as 'similarity' is likewise a matter of convention of cultural. In this occasion, readers should make precise decision on both a double and a replica is a perfect iconic sign of 'original' as its object? The term similarity should not focus on relationship between the picture/illustration and its title (object), but between the image and a previously cultural content [10].

In Eco's perspective, the whole iconic will be coincide with identity or it could be said as indiscernibility, later on Semiotics will be involving the idea of 'complete iconic matters.

In context of assuming the article (title) and its sign to be similar in whole identical the situation takes a role to be logically absurd, as Peirce had pointed out as: the ultimate interpretant, which is able to encompass the Object entirely, should be the object itself.

Based on those three models of representation for readers in postmodern era, people know how to assume articles. Some articles emerge to be un-decoded index that create several interpretations. Through symbols in form of image, readers are able to create links between the articles and the reality behind that article.

The internet of thing reached the very high tide of human interaction to the computer. By its consequence, people received technology instantly, accept knowledge in seconds and construct opinions directly without any background valid information. Vagueness in construction opinion in internet became the most researchable subject in informatics and language area. In triadic or dyadic system of Semiotics, both image and text will represent reality; unfortunately, the reality is virtually shaped by people in digital era.

In an online news, people sometimes highlighted the title and he images that they assumed those were related to each other. Between icon-where the signs physically resembled to the things, index-implied signs and symbol-which is conventionally learned sign, should have accordance to create validity of articles in online news.

The text constitutes a parasitic message designed to connote the image, to 'quicken' it with one or more second-order signified. In other words, and this is an important historical reversal [3]. In writing about the impact of emotion and emotional responses on the process of perception, Barry cites research which shows that, "the brain's amygdala, the seat of our emotions dates back to the reptilian era and still plays a primary and dominant role in all our perception" [4]. The perception of correlating process in human mind happens when they read the headline of article and its image presenting the event.

In some cases, hoax news appeared as the effect of sustainability of news maker to the reader-self-filtering aspect that should be owned by every reader. This happened as the form of bias information that absolutely refers to emerge different situation to the public. As it could be seen recently, hoax news is viral and widespread through every single personal gadget. We can't really remove the connotations of an image and this beholds a purely literal, denoted image. If we could we would comprehend the image at what Barthes calls the 'first degree of intelligibility', the point at which we see more than shapes [5].

\section{Semiotics Analysis}

The headlines taken from local news posted online is more susceptible to be hoax news caused by inaccuracy and incompatible of their text and images. These samples that would be analysed by Semiotics are taken from several headlines that are posted in online news. The data analysis might contain screenshot-image to give more reliable data and also to give more authentic source of the news.

\subsection{News about white luminous Mecca and Medina}

This local headline news stated "Mecca and Medina Evidently Seen Luminous from Outer Space". It's taken from tribunjabar.co.id in April 2015 edition [6]. The headline was stating that white luminous appeared from particular places which exactly could be analysed by two stages of analysis in Semiotics.

Based on that relation of engagement between text and image, it is obviously connected to each other as one whole package. The text stated white luminosity which with supported by the image showed part of the particular country (area) beam and luminous. The news had been really reliable since the news provider served both text and image in one package that seemed correlative. The readers would have believed of what they had read and would have probably shared the news because it related with specified glorious religion.

But, in fact, the news had weak point to be reliable for some readers, since the information served in that news were not precisely correct to the reality. The news involved some people as the main characters to strengthen the fact they believed. The truth about this text and image had been researched by some people.

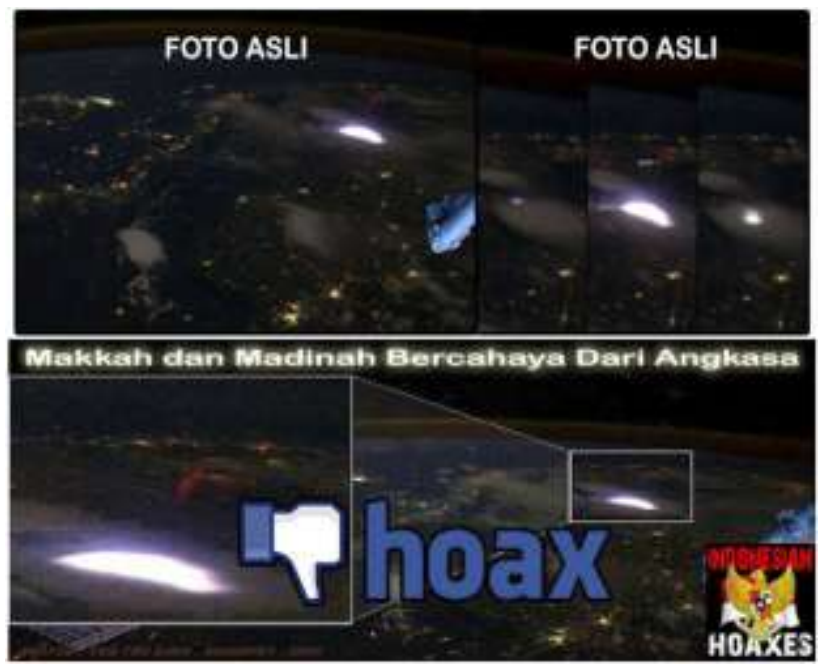

Fig. 1: Hoax 
The fact about the image: it was the lightning photograph captured by the ISS (International Space Station) that was crossing by between Myanmar and Malaysia. It was not even in Middle-east area as the title of article stated.

The intention of this attaching of text and image was not obviously clear, except to get popularity-when it was executed by personal- or even to attract viewers to visit its page. Furthermore, the intention might be as a religion identity that showed gracious. By Semiotics analysis, the correlation between text and image is acceptable, since it supported to each other (text and image), but when it should be proved about its authenticity, it had discursive point between them.

By the dominant reader's perspective, this could be received as real story. Since the news were covered by religious matter blown up the vagueness between real and hoax in some news served. Along the process of perceiving, people insist to be faithful in a news covered by religious matter as shown in the image. The news title was a huge eye-seized line to the reader's mind. They, otherwise, related the title with the image that made them deceived by those two items within.

As Semiotics term purposed to be the fence of human point of view to the simulacrum; it takes rules to make image and its components interconnected. When the components have been interconnected to those Semiotics; it could be assumed that the image is representative to the articles.

For some negotiated readers' perspective, they do not always relate some news to particular religion. They believe what they see, but otherwise, they will check the news and its interconnection with the other sources they could take from another website. After the process of checking to different sources, they usually will construct the caption or their point of view toward the news. By the significant and signifier, they received, article/tile and its illustration turn to be devotedness of their own believe without distractions.

\subsection{News about Syrian Boys Sleeping with His Parents}

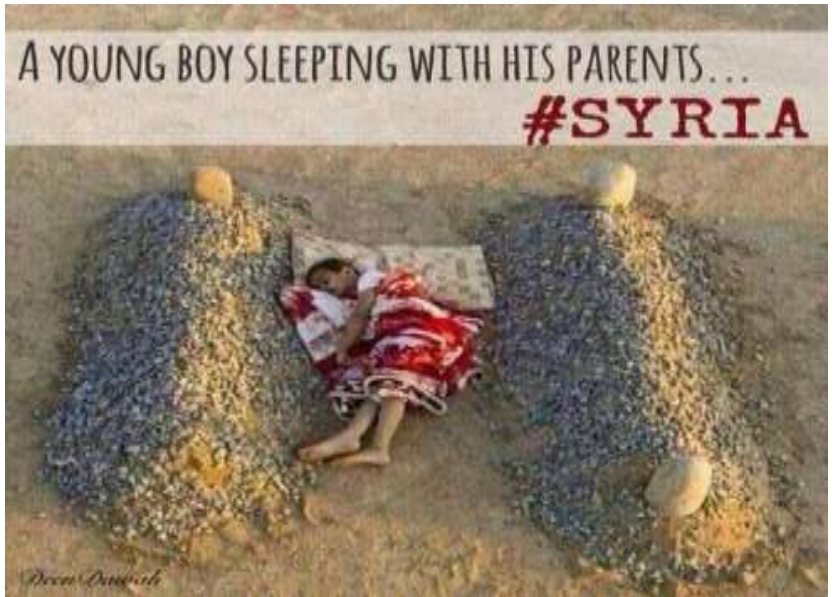

Fig. 2: Sleeping Image 1

There's a quite big chance that everybody had seen this dramatic picture of a Syrian boy covered by a blanket sleeping between the two graves of his dead parents. It went viral and widespread after some big accounts published it yesterday on internet, especially social media. The image touted as an orphaned Syrian boy sleeping between the graves of his murdered parents has been sweeping through social media and is being used to decry the deteriorating situation in Bashar al-Asaad's country [7].

The photo appeared with a headline or caption leading viewers to believe that this is an orphaned Syrian child that had lost his parents in the unrest there. Since the conflict of Syria became the majority of news consumption for people in the world, then some photos with the articles came up frequently in media online. The news told about the condition of children in Syria whose parents were murdered.
Based on the Semiotics analysis that involving text and image, there was nothing wrong with the article or the caption attached in the image. The correlation between text and image happened dramatically in this case. It had connotative meaning by putting the word parents which was illustrated by only couple of graves. The engagement between those aspect, text and image, was truly connected. The article or headline (text) said sleeping and it has appropriate simulacrum.

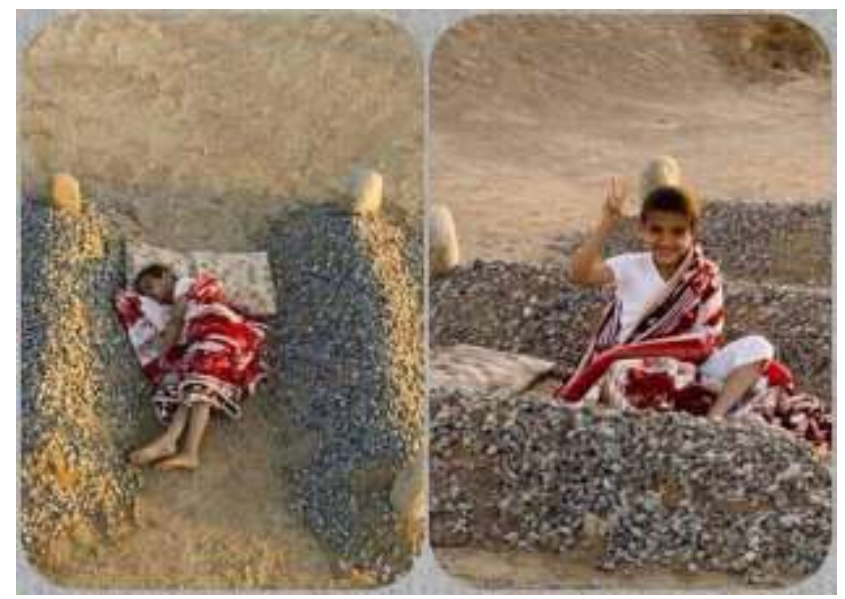

Fig. 3: Sleeping Image 2

But in fact, however, is that the image is a staged photo. It was purposed as the art work of photography. It was taken not in Syria but in Saudi Arabia. The other fact that, the boy was not really an orphan; he was the nephew of a photographer.

The photo maker of this artwork cannot be blamed at all for this propaganda image. Abdul Aziz al Otaibi, a photographer from Saudi Arabia, has made it clear that he is quite upset that people have appropriated his image for a Syrian propaganda campaign. This photo was intended as an artistic statement about a child's love for his parents.

Somehow, people tended to be dramatic and emotional knowing this photography, then it was posted in media which became viral and created diverse responds and criticisms.

Based on Semiotics analysis, this photograph had a match proportion between text and image. Its compatibility was engaged by those aspects showed in the media. Furthermore, it was acceptable as correlative text and image, but it became discursive when the fact appeared from the reliable source.

Some dominant reader's view the connected index and symbol as in the picture above as a real story. After they reconcile, it could result awareness of their faith of believing to some particular religions. As it stated in the title of the news, it has a hashtag refers to country with majority Moslem that has a conflict (war). By the representation of a child, war/conflict and graves, it has emerged the emotional matter to the reader. They, since the news were covered by religious matter, insist to be faithful in that article/news.

For some counter-hegemonic perspective, they will attack the article by the argument they have created. It contains a lot of strategies to construct the vagueness based on their empirical background to some information. Some people are in purpose to argue, some people do not know about the truth that make them arguing everything. It is such a golden age to this type of readers to search and argue about everything they have read.

Those type of readers affect to the existence of hoaxes in internet that are widespread instantly.

\section{Conclusion}

The tool of analysis, Semiotics, has become the most useful instrument in finding the correlation between text and image. Otherwise, it could also as the discursive research finding matter which showed inaccuracy of its information between text and 
image. Theories applied in this research were generally supported in finding the unmatched information that was supported by image as it could be seen from the two online news that were contagiously viral in internet. Based on the analysis, it could be inferred that the engagement point of text and image relation in those news (articles) were compatible. They were appropriate in Semiotic; but then it also became discursive along with the truth data behind all of the captured-images. Future works are going to be implementation and observation this method deeply by inserting reasons of posting discursive text and image in online media. The author hopes that the results as same as the hypothesis. Another work can composite another method in Semiotics area in improving the other findings.

\section{Acknowledgement}

The author wishes to thank Widyatama University and Yayasan Widyatama.

\section{References}

[1] Short, T. L. 2007. Pierce's Theory of Signs. Cambridge University Press

[2] Danesi, M. 2002. Understanding Media Semiotics. Arnold Publisher.

[3] Barthes, R. 1977. Image-Music-Text. Fontana.

[4] Barry, A. M. S. 1997. Visual Intelligence: Perception, Image, and Manipulation in Visual Communication. State University of New York Press.

[5] Bateman, J. 2015. Text and Image: A Critical Introduction to the Visual/Verbal Divide. George Mason University

[6] Serba Serbi Tribun. http://jabar.tribunnews.com/2015/04/17/subhanallah-mekkahmadinah-terlihat-bercahaya-putih-dari-luar-angkasa.

[7] Warner, T. H. 2014. https://www.breitbart.com/nationalsecurity/2014/01/18/popular-photo-of-syrian-child-sleepingbetween-graves-of-parents-a-hoax/.

[8] Hall, S. 2001. Encoding/decoding. In Centre for Contemporary Cultural Studies (Ed.), Culture, Media, Language: Working Papers in Cultural Studies, 1972-79. London: Hutchinson, pp. 128-138.

[9] Parkin, F. 1972. Class Inequality and Political Order. Granada. 